\title{
Predictors of Spontaneous Bacterial Peritonitis in Patients with Cirrhotic Ascites
}

\author{
Khaled Metwally*, Tamer Fouad, Medhat Assem, Eman Abdelsameea and Mohamed Yousery \\ Hepatology and Gastroenterology department, National Liver Institute, Menoufia University, Egypt
}

\begin{abstract}
Background and Aims: Spontaneous bacterial peritonitis (SBP) is a serious complication of liver cirrhosis and a prognostic model to predict it is needed. This study was designed to test the ability of different laboratory tests and the new scoring system by Wehmeyer and colleagues (consisting of age, C-reactive protein (CRP) and platelet count) to predict it. Methods: Three-hundred patients admitted to the National Liver Institute, University of Menoufia, Egypt (2015-2016) with liver cirrhosis and ascites were included in our study. SBP was diagnosed if ascetic neutrophil count was $\geq 250 / \mu \mathrm{L}$ with no sign of secondary peritonitis. Results: The patient population had age range of $29-81$ years old, was $60 \%$ men and showed a majority (91.7\%) with primary cause of liver disease being hepatitis $\mathrm{C}$. By univariate analysis, associations with age, total bilirubin, aspartate aminotransferase level, creatinine level, international normalized ratio, model for endstage liver disease score, total leucocytic count, platelet count and CRP level were significant. By multivariate analysis, independent predictors were age, platelet count and CRP level ( $p=0.004,0.013$ and $<0.001$, respectively). CRP at a cut-off point $\geq 13.5 \mathrm{mg} / \mathrm{L}$ could predict SBP (sensitivity of $86.4 \%$ and specificity of $66.0 \%)$. Wehmeyer's SBP scoring system was predictive $(p<0.001)$; only $4 \%$ of patients with 0 score developed SBP (CRP cut-off of $30 \mathrm{mg} / \mathrm{L}$ ), while $92.8 \%$ with score of 3 or 4 developed SBP. By using our modified Wehmeyer score with CRP cut-off value of $13.5 \mathrm{mg} / \mathrm{L}$, no patient with 0 score developed SBP. Conclusions: Age, CRP level and platelet count are independent predictors for SBP and a scoring system including them could easily predict the condition. SBP diagnosis could be excluded in patients with 0 score, using CRP cut-off value of $13.5 \mathrm{mg} / \mathrm{L}$.
\end{abstract}

Citation of this article: Metwally K, Fouad T, Assem M, Abdelsameea $E$, Yousery M. Predictors of spontaneous bacterial peritonitis in patients with cirrhotic ascites. J Clin Transl Hepatol 2018;6(4):372-376. doi: 10.14218/JCTH.2018.00001.

\section{Introduction}

Liver disease burden is increasing all over the world, and in Egypt it is manifesting more frequently due to the high

Keywords: CRP; Predictors; SBP; Cirrhosis; Scoring.

Abbreviations: AST, aspartate aminotransferase; CRP, C-reactive protein; HCV, hepatitis $C$ virus; MELD, model of end-stage liver disease; SBP, spontaneous bacterial peritonitis.

Received: 4 January 2018; Revised: 7 June 2018; Accepted: 22 June 2018

*Correspondence to: Khaled Metwally, Liver and Gastroenterology Unit, National Liver Institute, University of Menoufyia, Menofyia Governorate, Egypt. Tel: +20 100-0486019, Fax: + 20-48-2222740,E-mail: kh_m55555@yahoo.com prevalence of hepatitis $\mathrm{C}$ virus (HCV). ${ }^{1}$ Patients with advanced liver disease are at high risk of developing severe complications, one of which is spontaneous bacterial peritonitis (SBP). Its incidence was reported to reach $25 \%{ }^{2,3}$ among the cirrhotic patients with ascites, with mortality rates reported at $20-40 \% .{ }^{4,5}$ As such, there is a real need to find a noninvasive prognostic scoring system to predict patients more liable to develop SBP, as early treatment could reduce the mortality rate. ${ }^{2}$ Multiple laboratory tests have been introduced as predictive for SBP, including C-reactive protein (CRP) level, ${ }^{6,7}$ platelet count, ${ }^{6-8}$ impaired prothrombin time, ${ }^{9}$ serum creatinine level, ${ }^{9}$ bedside liver disease scoring systems like Child-Pugh ${ }^{8}$ and the model of end-stage liver disease (MELD) scores, ${ }^{10}$ but only contradictory data are available. A new simple SBP prognostic scoring system consisting of age, platelet count and CRP level was recently developed by Wehmeyer et al. ${ }^{7}$

Our aim was to study the ability of different clinical and laboratory variables that could predict the development of SBP in Egyptian cirrhotic patients with ascites, and also to test the scoring system consisting of age, CRP level and platelet count and its cut-off values.

\section{Methods}

Adult patients ( $>18$ years old) with liver cirrhosis and ascites admitted for various reasons to the National Liver Institute Hospital, University of Menoufia, from March 2015 to December 2016 were included in our study. Clinical examination findings and laboratory data were collected on admission. We excluded patients with malignancy, hemorrhagic ascites, evidence of secondary peritonitis or those receiving antibiotic treatment at the time of paracentesis, to exclude those patients with other systemic infections related to respiratory or urinary tract infection. Our study was approved by the ethical committee of the National Liver Institute, University of Menoufia.

Diagnostic paracentesis was carried out in all the patients and the samples were evaluated for polymorphonuclear cell (PMNs) count, total protein level, albumin level, Gram stain, bacteriological culture, and bedside pathologic assessment to exclude the presence of atypical cells. SBP was defined, according to the EASL Guidelines $2010,{ }^{11}$ as ascetic neutrophil count $\geq 250 / \mu \mathrm{L}$ with or without a positive culture of the ascetic fluid, in the absence of any finding suggestive of secondary peritonitis. The scoring system used by Wehmeyer and colleagues was tested in our patients, using a scale of 0 to 4 , where we gave one point for age $>60$ years, one point if platelet count was $<100,000 / \mathrm{mL}$, one point if CRP was 
Metwally K. et al: Predictors of SBP in cirrhotic ascites

Table 1. Patients' characteristics

\begin{tabular}{|c|c|c|c|c|c|c|}
\hline \multirow[b]{3}{*}{ Variable } & \multicolumn{6}{|l|}{ SBP } \\
\hline & \multicolumn{3}{|l|}{ Negative } & \multicolumn{3}{|l|}{ Positive } \\
\hline & Mean \pm SD & Range & Median & Mean $\pm S D$ & Range & Median \\
\hline Age, y & $54.5 \pm 8.6$ & $29-81$ & 56 & $58.9 \pm 8.3$ & $33-70$ & 60 \\
\hline $\begin{array}{l}\text { Bilirubin, } \\
\mathrm{mg} / \mathrm{dL}\end{array}$ & $2.8 \pm 2.7$ & $0.5-26$ & 2 & $5.1 \pm 4.7$ & $0.5-26$ & 2 \\
\hline Albumin, g/dL & $2.7 \pm 0.5$ & $1.2-4.1$ & 3 & $2.6 \pm 0.5$ & $1.3-3.5$ & 3 \\
\hline INR & $1.8 \pm 0.5$ & $1.1-6.2$ & 1.7 & $2.2 \pm 0.8$ & $1.3-5.9$ & 2 \\
\hline MELD & $18.7 \pm 6.7$ & $7-46$ & 17 & $25.1 \pm 7$ & $12-49$ & 23 \\
\hline $\begin{array}{l}\text { Creatinine, } \\
\text { mg/dL }\end{array}$ & $1.5 \pm 0.9$ & $0.5-6.1$ & 1 & $2.1 \pm 1.7$ & $0.5-8.9$ & 2 \\
\hline TLC, mL & $8,167.7 \pm 3,858$ & $580-28,400$ & 7,500 & $10,005.1 \pm 5,350.7$ & $3,700-35,000$ & 8900 \\
\hline Platelet, mL & $113,257.3 \pm 46,652.4$ & $20,000-303,000$ & 110,000 & $73,678 \pm 31,110.7$ & $21,000-174,000$ & 67,000 \\
\hline $\mathrm{CRP}, \mathrm{mg} / \mathrm{L}$ & $12.6 \pm 6.6$ & $5-44$ & 11 & $29.1 \pm 13.6$ & $8-64$ & 27 \\
\hline$A L T, U / L$ & $53.8 \pm 153.6$ & $10-2,004$ & 33 & $85.4 \pm 105.9$ & $13-611$ & 46 \\
\hline AST, U/L & $62.5 \pm 104.7$ & $16-1,390$ & 42 & $153.7 \pm 242.7$ & $24-1,374$ & 79 \\
\hline
\end{tabular}

Abbreviations: ALT, alanine transaminase; AST, aspartate transaminase; CRP, C-reactive protein; INR, international normalized ratio; MELD, model for end-stage liver disease; SBP, spontaneous bacterial peritonitis; SD, standard deviation; TLC, total leukocytic count.

between 30 and $60 \mathrm{mg} / \mathrm{L}$, and two points if CRP was above $60 \mathrm{mg} / \mathrm{L}^{7}$

\section{Statistics}

Patients were categorized into two groups according to the presence or absence of SBP. Data was statistically analyzed using SPSS version 20 for Windows, and $p$-value $<0.05$ was considered statistically significant for all the analyses. Data are shown as mean, range or value. Independent samples $t$-test was used to examine the difference between the two groups for continuously-distributed variables, while chi-square test was used for categorical variables. Significant factors were tested in a univariate binary logistic regression analysis, and then only significant variables were entered in a stepwise multivariate logistic regression analysis to identify the independent predictors for the occurrence of SBP.

\section{Results}

Our study included 300 patients with liver cirrhosis and ascites, of ages ranging 29-81 years old, and predominantly male (180 males and 120 females). The primary cause of liver disease was chronic hepatitis C (275 patients; $91.7 \%$ ), hepatitis B (20 patients; $6.6 \%$ ) and cryptogenic cause (5 patients; $1.7 \%)$. Diagnostic paracentesis revealed that 59 patients $(19.6 \%)$ were diagnosed with SBP. Patients' characteristics are shown in Table 1.

Age had a highly statistically significant difference between patients with or without SBP $(p=0.001)$, while sex or the presence or absence of diabetes mellitus had no statistical

Table 2. Different variables and their statistical significant difference between patients with and without SBP

\begin{tabular}{|c|c|c|c|c|c|}
\hline Variable & Independent sample $t$-test & $p$-value* & Variable & Chi-square & $p$-value* \\
\hline Age, $Y$ & 3.51 & 0.001 & Sex & 0.17 & 0.67 \\
\hline Bilirubin, mg/dl & 3.58 & 0.001 & DM & 2.05 & 0.15 \\
\hline INR & 4.15 & $<0.001$ & Child-Pugh & 0.61 & 0.73 \\
\hline Albumin, g/dl & -1.29 & 0.19 & SBP scoring system & 79.46 & $<0.001$ \\
\hline Creatinine mg/dl & 2.82 & 0.006 & & & \\
\hline ALT U/L & 1.49 & 0.13 & & & \\
\hline AST U/L & 2.85 & 0.006 & & & \\
\hline TLC, ml & 3.02 & 0.003 & & & \\
\hline Platelet, ml & -7.84 & $<0.001$ & & & \\
\hline CRP, mg/L & 9.11 & $<0.001$ & & & \\
\hline MELD & 6.59 & $<0.001$ & & & \\
\hline
\end{tabular}

${ }^{*} p$-value significant if $<0.05$.

Abbreviations: ALT, alanine transaminase; AST, aspartate transaminase; CRP, C-reactive protein; DM, diabetes mellitus; INR, international normalized ratio; MELD, model for end-stage liver disease; SBP, spontaneous bacterial peritonitis; TLC, total leukocytic count. 
Metwally K. et al: Predictors of SBP in cirrhotic ascites

Table 3. Logistic regression analysis displaying independent predictors of the occurrence of SBP

\begin{tabular}{llllll}
\hline Variable & B & S.E. & Wald & Sig. & Exp(B) \\
\hline Age, Y & 0.082 & 0.029 & 8.241 & 0.004 & 1.086 \\
Bilirubin & 0.010 & 0.072 & 0.020 & 0.89 & 1.010 \\
INR & 0.165 & 0.585 & 0.080 & 0.78 & 1.180 \\
MELD & 0.100 & 0.090 & 1.233 & 0.27 & 1.105 \\
Creatinine & 0.045 & 0.325 & 0.019 & 0.89 & 1.046 \\
TLC, ml & 0.000 & 0.000 & 0.944 & 0.33 & 1.000 \\
Platelet, ml & 0.000 & 0.000 & 6.110 & 0.013 & 1.000 \\
CRP, mg/L & 0.205 & 0.033 & 37.989 & $<0.001$ & 1.228 \\
AST U/L & 0.002 & 0.001 & 1.936 & 0.16 & 1.002 \\
\hline
\end{tabular}

Abbreviations: AST, aspartate transaminase; CRP, C-reactive protein; INR, international normalized ratio; MELD, model for end-stage liver disease; SBP, spontaneous bacterial peritonitis; TLC, total leukocytic count.

significant difference ( $p=0.678$ and 0.152 , respectively). Table 2 shows the different variables with statistical significant difference between patients with and without SBP. Variables like serum total bilirubin, aspartate aminotransferase (AST), creatinine, international normalized ratio, total leukocytic count, platelet count and CRP showed a statistically significant difference between the two groups ( $p=0.001,0.006,0.006$, $<0.001,0.003,<0.001$ and $<0.001)$. On the other hand, variables like serum albumin and alanine aminotransferase had no statistical significant difference ( $p=0.198$ and 0.136). MELD score showed a highly statistically significant difference $(p<0.001)$ with positive correlation between the patients' MELD scores and the development of SBP, while Child-Pugh score failed to show such relation ( $p=0.737)$.

By univariate analysis, nine variables had a $p$ value of $<0.05$ as predictive factors of an episode of SBP: age, total bilirubin, AST, creatinine, international normalized ratio, MELD score, total leukocytic count, platelet count and CRP level. These variables were entered in a stepwise multivariate analysis, which showed that only age, platelet count and $\operatorname{CRP}(p=0.004,0.013$ and $<0.001$, respectively) were independently correlated with the risk of developing SBP. Table 3 shows the logistic regression analysis results of the independent predictors of SBP. Our results showed that CRP and platelet count could significantly differentiate between patient groups at a cut-off point of $\geq 13.5$ $\mathrm{mg} / \mathrm{L}$ and $\leq 82,500 / \mathrm{mL}$, respectively (sensitivity of $86.4 \%$ and $71.2 \%$, and specificity of $66.0 \%$ and $71.4 \%$, respectively).

Tables 4 and 5 show the diagnostic accuracy of CRP and platelet count in predicting SBP and the best cut-off values, as
Table 5. Best cut-off points of CRP and platelets to predict occurrence of SBP in the studied patients

\begin{tabular}{|c|c|c|c|}
\hline & \multicolumn{3}{|c|}{ Coordinates of the Curve } \\
\hline & $\begin{array}{l}\text { Positive if } \\
\text { greater than } \\
\text { or equal to }\end{array}$ & Sensitivity & 1-specificity \\
\hline $\mathrm{CRP}, \mathrm{mg} / \mathrm{L}$ & 13.5000 & 0.864 & 0.340 \\
\hline Platelet, ml & 82500.0000 & 0.712 & 0.286 \\
\hline
\end{tabular}

Abbreviations: CRP, C-reactive protein; SBP, spontaneous bacterial peritonitis

well as the receiver operating characteristic curves. When we tested our scoring system with a CRP cut-off value of $13.5 \mathrm{mg} / \mathrm{L}$, we found that no patient with 0 score developed SBP. Table 6 shows our modified Wehmeyer's SBP scoring system and the incidence of SBP, where we gave one point if CRP value was between 13.5 and $30 \mathrm{mg} / \mathrm{L}$, two points if between 30 and $60 \mathrm{mg} / \mathrm{L}$, and three points if more than $60 \mathrm{mg} / \mathrm{L}$.

\section{Discussion}

Cirrhosis increases the risk of developing bacterial infections and those patients are more vulnerable to death from sepsis than the normal population. ${ }^{12,13}$ Mortality may reach $70 \%$ due to the development of shock or multiorgan failure. ${ }^{14}$ Finding the prognostic factors that could evaluate the clinical condition of the hepatic patients and predict the occurrence of severe complications like SBP or even mortality is important for patient allocation on to the liver transplantation wait-list. The most widely used prognostic scoring systems for the general condition of such patients are the Child-Pugh and MELD, but still there is no agreement on a specific prognostic scoring system for the development of each severe complication. SBP is an example of such, a low ascetic fluid protein was found to be associated with high risk of its development but the search continues for a noninvasive scoring system. The new SBP prognostic scoring system developed by Wehmeyer et al., ${ }^{7}$ which depends on three parameters found to be related to SBP occurrence (age, platelet count and CPR level), is a simple and easyto-use scoring system as it depends on routinely assessed parameters for admitted patients.

In our study which included Egyptian patients suffering advanced liver disease, mostly secondary to hepatitis C infection, the incidence of SBP was $19.6 \%$, which shows how common it is to face this problem in this group of patients. We tested different variables, including the variables used in Wehmeyer's SBP scoring system, to see their relation to SBP prediction. The results showed that, although nine parameters

Table 4. Diagnostic accuracy of CRP and platelets to predict occurrence of SBP in the studied patients

\begin{tabular}{|c|c|c|c|c|c|}
\hline & \multirow[b]{2}{*}{ Area under the curve } & \multirow[b]{2}{*}{ Std. error* } & \multirow[b]{2}{*}{ Asymptotic sig. ${ }^{\dagger}$} & \multicolumn{2}{|c|}{ Asymptotic 95\% confidence interval } \\
\hline & & & & Lower boundary & Upper boundary \\
\hline CRP mg/L & 0.875 & 0.029 & $<0.001$ & 0.819 & 0.931 \\
\hline Platelet count, ml & 0.767 & 0.032 & $<0.001$ & 0.703 & 0.831 \\
\hline
\end{tabular}

*Under the nonparametric assumption;

${ }^{\dagger}$ Null hypothesis: true area $=0.5$.

Abbreviations: CRP, C-reactive protein; SBP, spontaneous bacterial peritonitis. 
Metwally K. et al: Predictors of SBP in cirrhotic ascites

Table 6. Our modified Wehmeyer's SBP scoring system and the incidence of SBP

\begin{tabular}{llllllll}
\hline & \multicolumn{7}{l}{ Modified Wehmeyer et al. ${ }^{7}$ SBP scoring system, $n(\%)$} \\
\cline { 2 - 7 } SBP & 0 & 1 & 2 & 3 & 4 & 5 & Total \\
\hline Negative & $58(100)$ & $120(94.5)$ & $55(72.4)$ & $6(25)$ & $2(15.4)$ & $0(0)$ & $241(80.3)$ \\
Positive & $0(0)$ & $7(5.5)$ & $21(27.6)$ & $18(75)$ & $11(84.6)$ & $2(100)$ & $59(19.7)$ \\
Total & 58 & 127 & 76 & 24 & 13 & 2 & 300 \\
\end{tabular}

Abbreviation: SBP, spontaneous bacterial peritonitis.

had a statistical difference for SBP occurrence (age, total bilirubin, AST, creatinine, international normalized ratio, total leukocytic count, platelet count, CRP level and MELD score), only age, platelet count and CRP level could independently predict SBP.

Regarding age, there is an association between increasing age and the susceptibility to infections due to impaired immunity with aging. ${ }^{15,16}$ Also, aging is an adverse prognostic factor in most liver diseases, with increasing morbidity and mortality compared to young patients. ${ }^{17,18}$

Low platelet count is common in chronic liver disease, due to splenic platelet sequestration, increase in its breakdown, or decrease in its production. It has been used as an indirect indicator of portal hypertension and liver disease severity. ${ }^{19-22}$ Also, as infections and especially sepsis produce thrombocytopenia, ${ }^{23}$ it was used as a predictor of SBP with low ascetic fluid protein. $^{8}$

Measurement of CRP could be considered as a limitation to this study. Although CRP is a well-known parameter for detecting inflammation or infection in the general population, ${ }^{24,25}$ it was considered by Le Moine et $a .^{26}$ as a weak predictor for infection in advanced liver disease because its basal level is commonly higher than normal in cirrhotics (owing to the underlying liver disease) and as it is produced mainly by hepatocytes (it does not increase so much with infection in patients with advanced cirrhosis). Our explanation is that, their study was conducted on 57 patients, 19 of which had infection on admission but only 7 of which had SBP and the other 12 had different causes of bacteremia; besides, they reported that CRP was correlated with interluekin- 6 and they concluded that it was a marker for diagnosis of SBP. Also, Park et al. ${ }^{27}$ reported that end-stage liver cirrhotic patients with bacteremia showed elevated CRP that was greater than in those without bacteremia, but these values were less than when there was bacteremia without cirrhosis. On the other hand, CRP was found to indicate a serious infection in cirrhotics if it was significantly high. ${ }^{28}$ Also, Guler et al. ${ }^{29}$ found significantly high CRP values in the SBP and the bacteriascites groups compared to the noninfected patient group $(68.4,68.3$ and $6.5 \mathrm{mg} / \mathrm{L}$, respectively). Wehmeyer et al. ${ }^{7}$ found the same results and included such in their three-parameter scoring system by giving one point if its level is more than $30 \mathrm{mg} / \mathrm{L}$ and two points if it is more than $60 \mathrm{mg} / \mathrm{L}$.

In our validation of the Wehmeyer SBP scoring system, we found higher scores (scores of 3 and 4 ) to be correlated significantly with the occurrence of $\operatorname{SBP}(p<0.001)$. A 0 score was able to rule out SBP correctly in most cases; only 4 patients out of 100 with 0 score developed SBP. According to our modification to the scoring system (one point was given if the CRP value was between 13.5 and $30 \mathrm{mg} / \mathrm{L}$, two points if between 30 and $60 \mathrm{mg} / \mathrm{L}$, and three points if more than $60 \mathrm{mg} / \mathrm{L}$ ), the results showed that scores of 4 or 5 are good predictors of SBP (only two patients with score of 4 , out of 13 patients, did not have SBP, while both patients with score of 5 had SBP). On the other hand, scores of 0 or 1 could be used to exclude SBP diagnosis (only 7 patients with score of 1 , out of 127 developed SBP, while no patient with score of 0 , consisting of 58 patients, developed it).

Based on these results, we conclude that SBP as a serious complication could be diagnosed by a simple scoring system that depends on age, platelet count and CRP level. Patients with score of 0 are unlikely to have SBP, while we should start treatment once they have a score of 4 or 5 . Ascitic sample testing and culture could be saved for patients with scores of 1,2 or 3 . Our results still need further work for validation in larger groups of patients.

\section{Conclusions}

Age, CRP level and platelet count are independent predictors for SBP, and a scoring system including them could easily predict the condition. SBP diagnosis could be excluded in patients with 0 score, using CRP cut-off value of $13.5 \mathrm{mg} / \mathrm{L}$.

\section{Acknowledgments}

These data were presented at the 27th Annual Conference for the Asian Pacific Association for the Study of the Liver (APASL2018).

\section{Conflict of interest}

The authors have no conflict of interests related to this publication.

\section{Author contributions}

Study concept and design (KM, TF), acquisition of data (KM, $T F, M A)$, analysis and interpretation of data (KM, MA), drafting of the manuscript (MY, EA, KM), critical revision of the manuscript for important intellectual content (KM, TF, MA, EA, MY), study supervision (MY, KM, MA).

\section{References}

[1] Kandeel A, Genedy M, El-Refai S, Funk AL, Fontanet A, Talaat M. The prevalence of hepatitis $C$ virus infection in Egypt 2015: implications for future policy on prevention and treatment. Liver Int 2017;37:45-53. doi: $10.1111 /$ liv. 13186.

[2] Lutz P, Nischalke HD, Strassburg CP, Spengler U. Spontaneous bacterial peritonitis: The clinical challenge of a leaky gut and a cirrhotic liver. World J Hepatol 2015;7:304-314. doi: 10.4254/wjh.v7.i3.304. 
[3] Kaymakoglu S, Eraksoy H, Okten A, Demir K, Calangu S, Cakaloglu Y, et al. Spontaneous ascitic infection in different cirrhotic groups: prevalence, risk factors and the efficacy of cefotaxime therapy. Eur J Gastroenterol Hepatol 1997;9:71-76. doi: 10.1097/00042737-199701000-00017.

[4] Cheong HS, Kang CI, Lee JA, Moon SY, Joung MK, Chung DR, et al. Clinical significance and outcome of nosocomial acquisition of spontaneous bacterial peritonitis in patients with liver cirrhosis. Clin Infect Dis 2009;48: 1230-1236. doi: 10.1086/597585.

[5] Tandon P, Garcia-Tsao G. Bacterial infections, sepsis, and multiorgan failure in cirrhosis. Semin Liver Dis 2008;28:26-42. doi: 10.1055/s-2008-1040319.

[6] Lata J, Fejfar T, Krechler T, Musil T, Husová L, Senkyrík M, et al. Spontaneous bacterial peritonitis in the Czech Republic: prevalence and aetiology. Eur J Gastroenterol Hepatol 2003;15:739-743. doi: 10.1097/01.meg.0000059160. 46867.62.

[7] Wehmeyer MH, Krohm S, Kastein F, Lohse AW, Lüth S. Prediction of spontaneous bacterial peritonitis in cirrhotic ascites by a simple scoring system. Scand J Gastroenterol 2014;49:595-603. doi: 10.3109/00365521.2013. 848471.

[8] Guarner C, Solà R, Soriano G, Andreu M, Novella MT, Vila MC, et al. Risk of a first community-acquired spontaneous bacterial peritonitis in cirrhotics with low ascitic fluid protein levels. Gastroenterology 1999;117:414-419. doi: 10.1053/gast.1999.0029900414.

[9] Shi KQ, Fan YC, Ying L, Lin XF, Song M, Li LF, et al. Risk stratification of spontaneous bacterial peritonitis in cirrhosis with ascites based on classification and regression tree analysis. Mol Biol Rep 2012;39:6161-6169. doi: 10 . 1007/s11033-011-1432-8.

[10] Obstein KL, Campbell MS, Reddy KR, Yang YX. Association between mode for end-stage liver disease and spontaneous bacterial peritonitis. Am J Gastroenterol 2007;102:2732-2736. doi: 10.1111/j.1572-0241.2007. 01485.x.

[11] EASL clinical practice guidelines on the management of ascites, spontaneous bacterial peritonitis, and hepatorenal syndrome in cirrhosis. J. Hepatol 2010; 53:397-417. doi: 10.1016/j.jhep.2010.05.004.

[12] Arvaniti V, D'Amico G, Fede G, Manousou P, Tsochatzis E, Pleguezuelo M, et al. Infections in patients with cirrhosis increase mortality four-fold and should be used in determining prognosis. Gastroenterology 2010;139: 1246-1256.e5. doi: 10.1053/j.gastro.2010.06.019.

[13] Foreman MG, Mannino DM, Moss M. Cirrhosis as a risk factor for sepsis and death: analysis of the National Hospital Discharge Survey. Chest 2003;124: 1016-1020. doi: 10.1378/chest.124.3.1016.

[14] Plessier A, Denninger MH, Consigny Y, Pessione F, Francoz C, Durand F, et al. Coagulation disorders in patients with cirrhosis and severe sepsis. Liver Int 2003;23:440-448. doi: 10.1111/j.1478-3231.2003.00870.x.

[15] Schneider EL. Infectious diseases in the elderly. Ann Intern Med 1983;98: 395-400. doi: 10.7326/0003-4819-98-3-395.
[16] Yoshikawa TT, Norman DC, Grahn D. Infections in the aging population. J Am Geriatr Soc 1985;33:496-503. doi: 10.1111/j.1532-5415.1985.tb05463.x.

[17] Kim IH, Kisseleva T, Brenner DA. Aging and liver disease. Curr Opin Gastroenterol 2015;31:184-191. doi: 10.1097/MOG.0000000000000176.

[18] Floreani A. Liver diseases in the elderly: an update. Dig Dis 2007;25: 138-143. doi: 10.1159/000099478.

[19] Qamar AA, Grace ND, Groszmann RJ, Garcia-Tsao G, Bosch J, Burroughs AK et al. Incidence, prevalence, and clinical significance of abnormal hematologic indices in compensated cirrhosis. Clin Gastroenterol Hepatol 2009; 689-695. doi: 10.1016/j.cgh.2009.02.021.

[20] Bashour FN, Teran JC, Mullen KD. Prevalence of peripheral blood cytopenias (hypersplenism) in patients with nonalcoholic chronic liver disease. Am J Gastroenterol 2000;95:2936-2939. doi: 10.1111/j.1572-0241.2000.02325.x.

[21] Poynard T, Bedossa P. Age and platelet count: a simple index for predicting the presence of histological lesions in patients with antibodies to hepatitis C virus. METAVIR and CLINIVIR Cooperative Study Groups. J Viral Hepat 1997 4:199-208. doi: 10.1046/j.1365-2893.1997.00141.x

[22] Sheikh MY, Raoufi R, Atla PR, Riaz M, Oberer C, Moffett MJ. Prevalence of cirrhosis in patients with thrombocytopenia who receive bone marrow biopsy. Saudi J Gastroenterol 2012;18:257-262. doi: 10.4103/1319-3767. 98431.

[23] Venkata C, Kashyap R, Farmer JC, Afessa B. Thrombocytopenia in adult patients with sepsis: incidence, risk factors, and its association with clinical outcome. J Intensive Care 2013;1:9. doi: 10.1186/2052-0492-1-9.

[24] Eklund CM. Proinflammatory cytokines in CRP baseline regulation. Adv Clin Chem 2009;48:111-136. doi: 10.1016/S0065-2423(09)48005-3.

[25] Castelli GP, Pognani C, Meisner M, Stuani A, Bellomi D, Sgarbi L. Procalcitonin and $\mathrm{C}$-reactive protein during systemic inflammatory response syndrome, sepsis and organ dysfunction. Crit Care 2004;8:R234-R242. doi: 10.1186/cc2877.

[26] Le Moine O, Devière J, Devaster JM, Crusiaux A, Durand F, Bernuau J, et al. Interleukin-6: an early marker of bacterial infection in decompensated cirrhosis. J Hepatol 1994;20:819-824. doi: 10.1016/S0168-8278(05)80155-2.

[27] Park WB, Lee KD, Lee CS, Jang HC, Kim HB, Lee HS, et al. Production of $\mathrm{C}$-reactive protein in Escherichia coli-infected patients with liver dysfunction due to liver cirrhosis. Diagn Microbiol Infect Dis 2005;51:227-230. doi: 10. 1016/j.diagmicrobio.2004.11.014.

[28] Preto-Zamperlini M, Farhat SC, Perondi MB, Pestana AP, Cunha PS, Pugliese $\mathrm{RP}$, et al. Elevated $\mathrm{C}$-reactive protein and spontaneous bacterial peritonitis in children with chronic liver disease and ascites. J Pediatr Gastroenterol Nutr 2014;58:96-98. doi: 10.1097/MPG.0000000000000177.

[29] Guler K, Vatansever S, Kayacan SM, Salmayenli N, Akkaya V, Erk O, et al. High sensitivity $\mathrm{C}$-reactive protein in spontaneous bacterial peritonitis with nonneutrocytic ascites. Hepatogastroenterology 2009;56:452-455. 